\title{
Selective Increase in T-Type Calcium Conductance of Reticular Thalamic Neurons in a Rat Model of Absence Epilepsy
}

\author{
Evdoxia Tsakiridou, ${ }^{1}$ Laura Bertollini, ${ }^{2}$ Marco de Curtis,, ${ }^{2}$ Giuliano Avanzini, ${ }^{2}$ and Hans-Christian Pape ${ }^{1,3}$ \\ 'Abteilung für Neurophysiologie, Medizinische Fakultät, Ruhr-Universität, D-44780 Bochum, Germany, ${ }^{2}$ Dipartimento \\ di Neurofisiologia, Istituto Nazionale Neurologico "Carlo Besta," I-20133 Milano, Italy, and 3nstitut für Physiologie, \\ Medizinische Fakultät, Otto-von-Guericke-Universität, D-39120 Magdeburg, Germany
}

\begin{abstract}
The properties of voltage-dependent calcium currents were compared in thalamic neurons acutely dissociated from a rat model of absence epilepsy, designated as Genetic Absence Epilepsy Rat from Strasbourg (GAERS), and from a Nonepileptic Control strain (NEC). Two populations of neurons were isolated: thalamocortical relay neurons of the nucleus ventrobasalis (VB) and neurons of the nucleus reticularis (RT) of the thalamus. Whole-cell patch-clamp analysis demonstrated an increase in the amplitude of the calcium $\left(\mathrm{Ca}^{2+}\right)$ current with a low threshold of activation $\left(I_{T}\right)$ in RT neurons of GAERS in comparison to that of the seizurefree rat strain $(-198 \pm 19 \mathrm{pA}$ and $-128 \pm 14 \mathrm{pA}$, respectively), whereas the sustained component $\left(l_{L}\right)$ was not significantly different. The kinetic properties, voltage dependence, and basic pharmacological sensitivity of the $\mathrm{Ca}^{2+}$ conductances were similar in the two populations of neurons. The amplitude of both $I_{\mathrm{T}}$ and $I_{L}$ in RT neurons increased after birth, and differences in $I_{T}$ between GAERS and NEC attained significance after postnatal day 11. At corresponding ages, the $\mathrm{Ca}^{2+}$ currents in VB thalamocortical relay neurons were not altered in GAERS in comparison to those in NEC.
\end{abstract}

We conclude that the selective increase in $I_{T}$ of RT neurons enhances the probability of recurrent intrathalamic burst activity, thereby strengthening the synchronizing mechanisms in thalamocortical systems, and, as such, represents a possible primary neuronal dysfunction that relates to the pathological increase in synchronization underlying the generation of bilateral and synchronous spike and wave discharges (SWDs) in an established genetic model of generalized epilepsy.

[Key words: thalamus, calcium currents, synchronization, spike and wave discharges, absence epilepsy, genetic model]

\footnotetext{
Received Aug. 1, 1994; revised Oct. 26, 1994; accepted Nov. 2, 1994

We thank Drs. C. Marescaux and M. Verones for letting us use the genetic absence epilepsy model GAERS, and Dr. Z. F. Kisvárday, Mrs. E. Tóth, and Mrs. U. Neubacher for help with immunohistochemical techniques. L.B. and M.d.C. are grateful to Dr. E. Wanke for making a recording setup available; E.T. and H.-C.P. acknowledge the generous support by Dr. U. T. Eysel. This research was supported by a grant from the Deutsche Forschungsgemeinschaft to H.-C.P. (Ey 8/17-3; Ey 8/17-4) and a European Neuroscience Program Grant to H.-C.P. and M.d.C. (No. 24).

Correspondence should be addressed to Hans-Christian Pape, Institut für Physiologie, Universitätsklinikum Otto-von-Guericke, Leipziger Strasse 44, D-39120 Magdeburg, Germany.

Copyright $(\mathcal{C} 1995$ Society for Neuroscience $0270-6474 / 95 / 153110-08 \$ 05.00 / 0$
}

Idiopathic generalized epilepsies in humans are characterized by the spontaneous occurrence of convulsive or nonconvulsive seizures that correlate with the abrupt appearance of bilateral synchronous spike and wave discharges (SWDs) on the electroencephalogram (EEG). Rhythmic SWDs that involve the entire cortical mantle from the very onset of the seizure are observed in the prototypical form of idiopathic epilepsy, the absence epilepsy, a presumably genetically determined disease (Metrakos and Metrakos, 1961; Roger et al., 1985; Berkovic et al., 1987; Commission on Classification and Terminology of the International League Against Epilepsy, 1989). The abrupt initiation and cessation of EEG discharges in generalized epilepsy suggested the hypothesis that a centrencephalic pacemaker structure projecting diffusely to the cortex could be responsible for bilateral and synchronous SWDs (Jasper and Kershman, 1941). Since the demonstration that SWDs in humans originale from the thalamus (Spiegel et al., 1951; Williams, 1953), the hypothesis that the mechanisms of thalamocortical synchronization could be implicated in the generation of spontaneous SWDs has been extensively investigated (Jasper and Droogleever-Fortuyn, 1946; Avoli and Gloor, 1982; Gloor and Fariello, 1988; Avoli et al., 1990).

It is widely recognized that the thalamus is intimately involved in cortical rhythmogenesis. During the transition toward quiescent sleep (from a desynchronized to a synchronized EEG state), thalamic nuclei generate rhythmic oscillations that progressively entrain the entire thalamocortical system to produce synchronous rhythmic activity termed spindling (Jahnsen and Llinás, 1984; Steriade and Deschenes, 1984; Steriade and Llinás, 1988; McCormick, 1992; Steriade et al., 1993). Important elements during the transition from desynchronized to synchronized states of the EEG are represented by the neurons of the nucleus reticularis thalami (RT). The RT is a shell-shaped nucleus formed by GABAergic neurons that project to the dorsal thalanuus and receive axon collaterals from both corticothalamic and thalamocortical fibers (Jones, 1985). Spindle activity is produced in the RT by the peculiar interplay between the intrinsic membrane properties, in particular, a $\mathrm{Ca}^{2+}$ conductance with low threshold of activation and $\mathrm{Ca}^{2+}$-dependent potassium or cationic currents (Avanzini et al., 1989; Huguenard and Prince, 1992; Bal and McCormick, 1993), and by the arrangement of RT synaptic interactions within the thalamocortical network (Steriade et al., 1986, 1987; Spreafico et al., 1991; von Krosigk et al., 1993). The potential role of RT neurons in sustaining the pathological synchronization underlying SWDs has been studied in a genetically based animal model that mimics the characteristics of human absence epilepsy, designated as Genetic Absence 
Epilepsy Rat from Strasbourg (GAERS; Marescaux et al., 1992). Absence-like seizures in GAERS occur spontaneously and are characterized by behavioral arrest, staring, and clonic twitching of the vibrissae, associated with high-amplitude SWDs at 7-11 $\mathrm{Hz}$. As for human generalized primary idiopathic epilepsies, in GAERS (1) the SWD trait is inherited, (2) the onset of seizures is age dependent, (3) seizure occurrence increases during phases of transition between sleep and wakefulness, (4) SWDs are suppressed by drugs effective against human absence epilepsy, (5) intercritical EEG activity is normal, and (6) there are no signs of neurological deficits or intercritical behavioral impairment. In agreement with a possible pathogenic role of the thalamus and, in particular, of the RT in the expression of absence seizures, SWDs in GAERS were demonstrated to originate from the lateral thalamic nuclei (Vergnes et al., 1987), and were abolished by local infusion of $\mathrm{Ca}^{2+}$ antagonists into the RT (Avanzini et al., 1993).

In order to gain insights into the cellular mechanisms that may be involved in the generation of SWDs, we analyzed voltagedependent $\mathrm{Ca}^{2+}$ currents in thalamocortical relay neurons and in RT neurons acutely isolated from GAERS and from a selected $100 \%$ seizure-free rat strain (nonepileptic controls, NEC).

\section{Materials and Methods}

Acutely isolated neurons were prepared from coronal slices $(400 \mu \mathrm{m})$, including the RT and the ventrobasal complex of the thalamus (VB) cut by vibratome or tissue chopper from 7-20-d-old GAERS and NEC after halothane anesthesia. Under a stereoscopic microscope, the RT was isolated from the adjacent VB by a cut along the external medullary lamina. The cellular content of the isolated tissue was verified with standard GABA or glutamic acid decarboxylase (GAD) immunostaining (Pape et al., 1994); tissue sections including RT contained a high concentration of immunopositive neurons, whereas GABAergic cells were extremely rare in VB tissue slices. RT cells and relay VB neurons from the same animal were separately dissociated using standard enzymatic/ mechanical procedures (Kay and Wong, 1986; Budde et al., 1992). Thalamic slices were incubated in oxygenated medium containing either trypsin (Sigma type XI; 1-4 mg/ml, 60-90 $\mathrm{min}$ at room temperature) or papain (Worthington; $14 \mathrm{U} / \mathrm{ml}, 10-20 \mathrm{~min}$ at $36^{\circ} \mathrm{C}$ ), bovine serum albumin $(0.5 \mathrm{mg} / \mathrm{ml})$ and (in mM) $120 \mathrm{NaCl}, 5 \mathrm{KCl}, 1 \mathrm{MgCl}_{2}, 1 \mathrm{CaCl}_{2}$, 20 PIPES, 25 dextrose ( $\mathrm{pH} 7.35$ ). After washing with enzyme-free medium, the neurons were mechanically dissociated by trituration. Neurons acutely dissociated from the VB were characterized by a large, multipolar, and GABA-negative soma, whereas RT neurons showed a fusiform soma intensely stained by GABA, giving rise to two major dendrites at opposite poles (see also Huguenard and Prince, 1992). Intracellular recordings were performed at room temperature from isolated neurons using the whole-cell variant of the patch-clamp technique (Hamill et al., 1981). Patch electrodes had an access resistance of 4-8 $\mathrm{M} \Omega$ Series resistance compensation $>50 \%$ was routinely utilized. Records were low-pass filtered at $2.5 \mathrm{kHz}$ (3-8 pole Bessel filter), and a $\mathrm{P} / 4$ pulse protocol (pCLAMP; Axon Instruments, USA) was used to remove leak and capacitive current interferences (see Budde et al., 1992). Two different extracellular solution perfused continuously at $0.1-1 \mathrm{ml} /$ min were utilized in the two laboratories to isolate $\mathrm{Ca}^{2+}$ currents. The solution used in the Bochum laboratory was (in mM) $120 \mathrm{NaCl}, 1 \mathrm{KCl}$, 10 D-mannitol, $2 \mathrm{CaCl}_{2}, 1 \mathrm{MgCl}_{2}, 20 \mathrm{TEA}-\mathrm{Cl}, 6$ 4-AP, 10 HEPES, and $1.5 \mu \mathrm{M}$ TTX. The solution in Milano laboratory was (in mM) 80 choline- $\mathrm{Cl}, 3 \mathrm{KCl}, 24$ glucose, $5 \mathrm{CaCl}_{2}, 1 \mathrm{MgCl}_{2}, 50 \mathrm{TEA}-\mathrm{Cl}, 84$-AP, 10 HEPES. The solution in the pipette contained (in mM) $128 \mathrm{~N}$-methylD-glucamine, $10 \mathrm{NaCl}, 1 \mathrm{CaCl}_{2}, 2 \mathrm{MgCl}_{2}, 11$ EGTA, $5 \mathrm{Na}_{2} \mathrm{ATP}, 0.5$ $\mathrm{Na}_{2} \mathrm{GTP}$, and 20 TEA-Cl ( $\mathrm{pH} 7.35$ ); or (in mM) 110 Tris- $\mathrm{PO}_{4}$ dibasic, 28 Tris-base, $2 \mathrm{MgCl}_{2}, 0.5 \mathrm{CaCl}_{2}, 11$ EGTA, $2 \mathrm{MgATP}, 0.2$ Tris-GTP, 20 creatine-phosphate, and $50 \mathrm{U} / \mathrm{ml}$ creatine-phosphokinase ( $\mathrm{pH} 7.4)$, in the Bochum and Milano laboratories, respectively.

\section{Results}

Whole-cell voltage-clamp experiments were performed in acutely dissociated neurons under conditions where $\mathrm{Ca}^{2+}$ currents are isolated. Depolarization of the membrane in the range between -80 and $-40 \mathrm{mV}$ from a holding potential of $-110 \mathrm{mV}$ evoked a transient $\mathrm{Ca}^{2+}$ inward current $\left(I_{\mathrm{T}}\right)$, whose amplitude increased with membrane depolarization (Fig. $1 A$ ). Positive to $-40 \mathrm{mV}$, a more sustained $\mathrm{Ca}^{2+}$ current $\left(I_{\mathrm{L}}\right)$ was additionally evoked, confirming the existence in RT neurons of two $\mathrm{Ca}^{2+}$ conductances with different activation threshold and kinetics (Huguenard and Prince, 1992). By comparing the basic characteristics of $\mathrm{Ca}^{2+}$ currents in RT neurons from GAERS and NEC, a striking difference in the amplitude of $I_{\mathrm{T}}$ was observed. As illustrated in Figure 1, depolarizing steps from a holding potential of -110 $\mathrm{mV}$ evoked much larger transient $I_{\mathrm{T}}$ currents in RT neurons from GAERS than in NEC, whereas the amplitude of the sustained $I_{\mathrm{L}}$ component was similar in the two groups of neurons. Currentvoltage relationships ( $I N$ histograms in Fig. $1 A$ ), constructed from a larger sample of neurons, demonstrated a significant increase in peak current amplitude at potential values negative to $-30 \mathrm{mV}$ in GAERS $(n=16)$ compared with that in NEC ( $n=$ 18), with no obvious shift in the peak current-voltage relationship. The sensitivity toward inorganic $\mathrm{Ca}^{2+}$ channel antagonists was not significantly different in RT neurons from the two groups of rats (data not shown). Nickel $(50 \mu \mathrm{M})$ reduced $I_{\mathrm{T}}$ by $54.0 \pm 21.4 \%(n=9)$ and by $37.7 \pm 8.8 \%(n=7)$, and $I_{\mathrm{L}}$ by $30.0 \pm 14.0(n=6)$ and by $33.1 \perp 7.6 \%(n=7)$ in RT neurons from GAERS and NEC, respectively. Cadmium $(50 \mu \mathrm{M})$ reduced $I_{\mathrm{T}}$ by $32.3 \pm 23.0 \%(n=7)$ in GAERS and by $57.1 \pm$ $23.2 \%(n=6)$ in NEC, while $I_{\mathrm{L}}$ was completely abolished in RT neurons from both groups of animals ( $n=10$ and $n=8$, respectively). Ethosuccimide, at a saturating concentration (5 $\mathrm{mM}$; Coulter et al., $1989 \mathrm{~b})$, reduced $I_{\mathrm{T}}$ by $18.3 \pm 6.9 \%(n=7)$ and by $19.5 \pm 2.9 \%(n=3)$ in GAERS and in the control group, similar to the reduction observed for the L-type current in the two populations of neurons $(18.1 \pm 6.3, n=5 ; 22.6 \pm$ $6.7, n=7$ ). Replacement of $\mathrm{Ca}^{2+}$ by barium ions $(2 \mathrm{~mm})$ resulted in an increase in amplitude of both $I_{\mathrm{T}}(23.2 \pm 6.3 \%, n$ $=7 \mathrm{GAERS} ; 18.1 \pm 3.4 \%, n=7 \mathrm{NEC})$ and $I_{\mathrm{L}}(43.4 \pm 13.4 \%$, $n=6$ GAERS; $20.8 \pm 10.5, n=3 \mathrm{NEC}$ ), as previously reported (Huguenard and Prince, 1992).

The transient and sustained $\mathrm{Ca}^{2+}$ current components were separated using a conditioning pulse protocol. A $100 \mathrm{msec}$ prepulse to $-50 \mathrm{mV}$ between the holding potential $(-110 \mathrm{mV})$ and the depolarizing voltage steps inactivated $I_{\mathrm{T}}$. The $I_{\mathrm{L}}$ current activated at membrane potentials positive to approximately -40 $\mathrm{mV}$, and the amplitude was not significantly different in RT neurons from GAERS and NEC (Fig. $1 B$ ). The $I_{\mathrm{T}}$ current was isolated by digital subtraction of the records obtained without and with the conditioning prepulse (Fig. 1C). In both groups of RT neurons, $I_{\mathrm{T}}$ was rapidly activated through depolarizing voltage steps and peaked at around $-50 \mathrm{mV}$. The average peak amplitude at $-50 \mathrm{mV}$ was significantly larger in GAERS $[-198 \pm$ $19 \mathrm{pA}$ (mean $\pm \mathrm{SEM} ; n=16)]$ than in NEC ( $128 \pm 14 \mathrm{pA}$; $n=17)(p<0.005)$. The amplitude of the T-type $\mathrm{Ca}^{2+}$ current in thalamic neurons increases significantly during postnatal development (see Fig. 3; see also Pirchio et al., 1990). The $I_{\mathrm{T}}$ amplitude differences observed in the present study are not related to development, since the two populations of RT neurons were isolated at the same postnatal age (postnatal days: $15.6 \pm$ $0.6, n=16$ GAERS; $15.6 \pm 0.6, n=18 \mathrm{NEC}$ ). The possibility that the differences in $I_{\mathrm{T}}$ amplitude resulted from differences in cell size could be largely rulcd out by using the whole-cell capacitance as an index of membrane surface area, and which was 
A
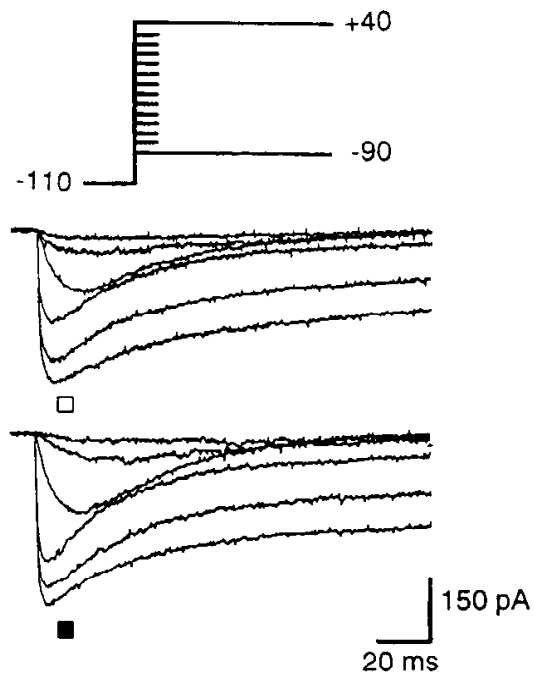

B
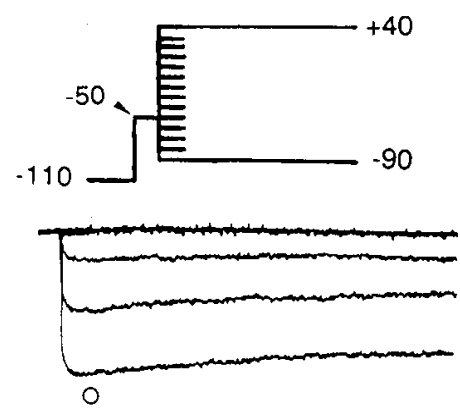

Figure 1. Whole-cell $\mathrm{Ca}^{2+}$ currents in RT neurons isolated from GAERS (closed symbols) and NEC (control; open symbols). A. Depolarizing voltage steps from $-110 \mathrm{mV}$ evoke a transient $\mathrm{Ca}^{2+}$ current, $I_{\mathrm{T}}$, followed by a sustained component, $I_{L}$, at more positive potentials. Note the increase in the transient component in GAERS, which is also indicated by the increase in the typical shoulder separating the two current components with different activation threshold in the $I N$ relationship. $B$, A conditioning prepulse to $-50 \mathrm{mV}$ (duration $100 \mathrm{msec}$ ) inactivates $I_{\mathrm{T}}$, and the remaining $I_{\mathrm{L}}$ is very similar in RT neurons from GAERS and NEC. $C$, Digital subtraction of $I_{L}$ (from experiments in $B$ ) from the total $\mathrm{Ca}^{2+}$ current (from $A$ ) isolates $I_{\mathrm{T}}$, whose amplitude is significantly increased in GAERS. $I / V$ relationships of peak currents are averaged from recordings in $n=16$ and $n=18$ RT neurons from GAERS and from NEC, respectively; numbers indicate examples shown as original traces; bars in $C$ represent SEM, asterisks mark significant differences (**, $p$ $<0.001 ; *, p<0.005$; two-tailed $t$ test) between GAERS and NEC. Neurons from both groups of animals were dissociated at postnatal day 16 .

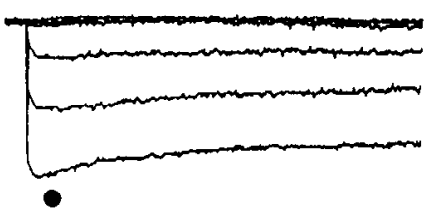

Difference, $A-B$
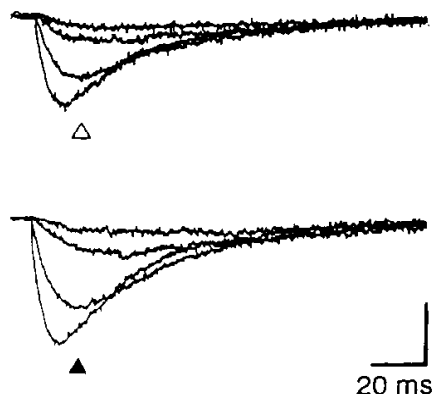

$150 \mathrm{pA}$
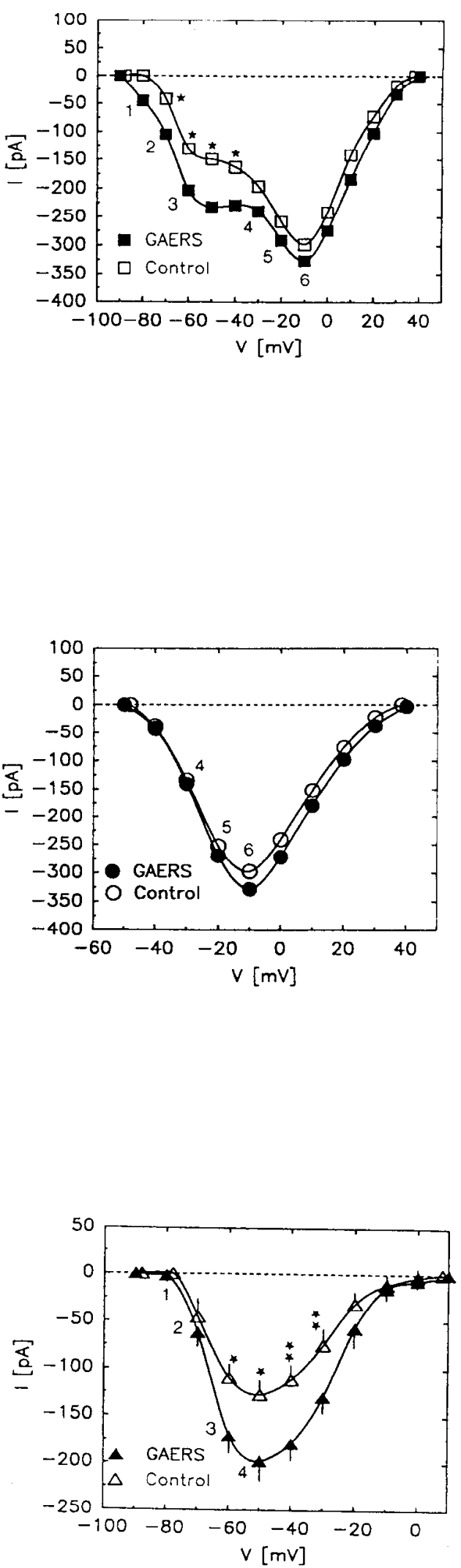

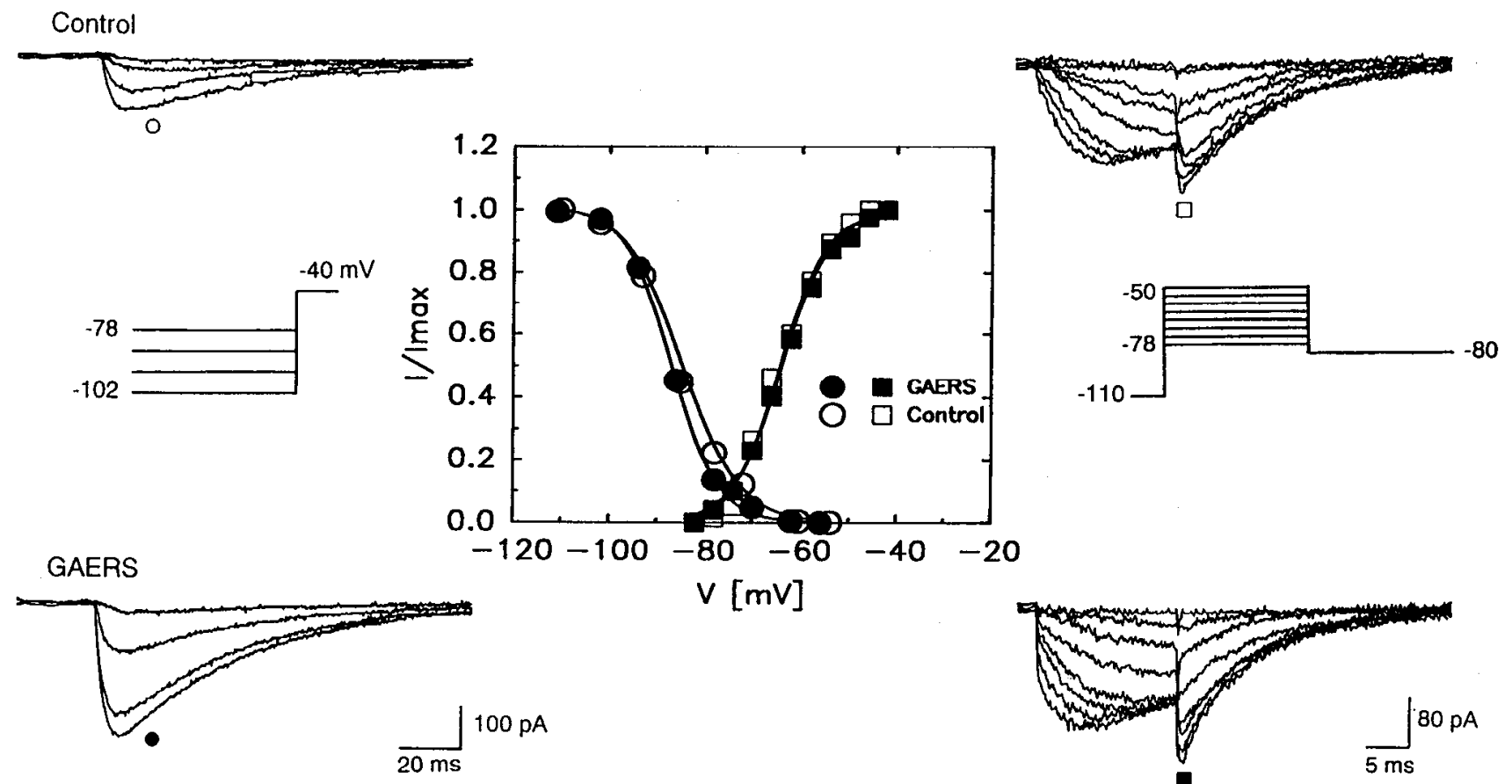

Figure 2. Similar voltage-dependent properties of $I_{\mathrm{T}}$ in RT neurons from GAERS (closed symbols) and NEC (control; open symbols). A, Steadystate inactivation of $I_{\mathrm{T}}$, as determined by varying a prepulse of $2 \mathrm{sec}$ duration between -110 and $-54 \mathrm{mV}$ before stepping to $-40 \mathrm{mV}$. The amplitude of $I_{\mathrm{T}}$ decreases with more positive values of the prepotential, indicating inactivation of the underlying conductance. $B$, Analysis of tail currents. $I_{\mathrm{T}}$ was activated with $15 \mathrm{msec}$ depolarizations to various potentials, and tail currents were evoked upon return to $-80 \mathrm{mV}$. $C$, The inactivation (circles) and activation curve (squares) of $I_{\mathrm{T}}$, as obtained from normalized peak currents (experiments in $A$ ) and tail current amplitudes $(B)$, are not significantly different for the two groups of cells. Histogram represents averaged data $(n=10-15)$; continuous curves are Boltzmann fits.

not significantly different in the two groups of neurons $(16.3 \pm$ $0.8 \mathrm{pF}, n=13 \mathrm{GAERS} ; 15.7 \pm 1.2 \mathrm{pF}, n=11 \mathrm{NEC}$ ).

A possible explanation for the altered expression of $I_{\mathrm{T}}$ in RT neurons may relate to changes in the voltage-dependent properties of the underlying conductance, for example, a shift in the inactivation and activation curves, or an alteration in the kinetics of the current. Since the time constant of activation of $I_{\mathrm{T}}$ could not be reliably determined, due to the relatively small amplitude of the current, the time-to-peak values were used as an approximation of the activation kinetics. The time-to-peak of $I_{\mathrm{T}}$ decreased with more positive membrane potentials: averaged values in the voltage range bctween 70 and $-40 \mathrm{mV}$ were between $21.2 \pm 1.6 \mathrm{msec}$ and $5.1 \pm 0.5 \mathrm{msec}$ in GAERS $(n$ $=11$ ) and between $17.8 \pm 1.6 \mathrm{msec}$ and $6.6 \pm 1.7 \mathrm{msec}$ in NEC $(n=10)$. The difference did not attain statistical significance (data not shown). The $I_{\mathrm{T}}$ currents inactivated completely with sustained depolarization, and they could not be elicited from holding potentials positive to $-60 \mathrm{mV}$. The time course of current decay was well fitted by a single exponential function of the form $I=A_{0}+A_{1} \exp (-t / \tau)$, where $I$ is the amplitude of the membrane current at the time $t, A_{0}$ and $A_{1}$ are the amplitude coefficients, and $\tau$ is the time constant. The time constant displayed very little voltage dependence, averaging $37.1 \pm 2.9$ and $25.3 \pm 0.9 \mathrm{msec}$ in GAERS $(n=15), 37.4 \pm 3.0$ and $26.5 \pm$ $2.6 \mathrm{msec}$ in NEC $(n=14)$ for depolarizations to -70 and -30 $\mathrm{mV}$, respectively (data not shown).

Figure $2 A$ illustrates samples of current records used to determine the voltage dependence of steady-state inactivation of the conductance underlying $I_{\mathrm{T}}$. A $2 \mathrm{sec}$ prepulse was incre- mented between -110 and $-54 \mathrm{mV}$ with $8 \mathrm{mV}$ steps, before delivering a constant test pulse at $-40 \mathrm{mV}$, subthreshold for $I_{\mathrm{L}}$ and near maximal for $I_{\mathrm{T}}$ activation. The peak current progressively reduced as the prepulse potential became less negative, indicating an increased level of inactivation. The normalized peak amplitudes of the currents were averaged and plotted against the prepotential (circles in histogram of Fig. 2). Approximation of a Boltzmann function ${ }^{1}$ to the data points indicated a range of steady-state inactivation of $I_{\mathrm{T}}$ that was largely overlapping in the two groups of RT neurons. The $I_{T}$ current was completely inactivated positive to $-60 \mathrm{mV}$; the values of half inactivation (at $-87.0 \pm 0.8$ and $-84.8 \pm 1.3 \mathrm{mV}$ ) and the slope of the curves $\left(4.9 \pm 0.4\right.$ and $\left.6.0 \pm 0.6 \mathrm{mV}^{-1}\right)$ were not significantly different in GAFRS $(n=15)$ and NEC $(n=12)$. The time course of recovery from inactivation of $I_{\mathrm{T}}$ was approximated best by a single exponential function (data not illustrated). The average time constant in RT neurons from GAERS (278.1 $\pm 20.4 \mathrm{msec} ; n=13$ ) was unaltered compared with that in NEC (274.9 $\pm 13.7 \mathrm{msec} ; n=14)$. To study the activation range of $I_{\mathrm{T}}$, tail currents were analyzed, obtained by repolarizing the membrane to $-80 \mathrm{mV}$ following $15 \mathrm{msec}$ depolarizing commands ( $4 \mathrm{mV}$ increments) from a holding potential of $-110 \mathrm{mV}$. The most depolarized command steps evoked nearly overlapping tail currents, indicating near-maximal activation of $I_{\mathrm{T}}$. With fur-

' The equation for the Boltzmann function was $I / I_{\max }=\left[1+\exp \left(\left(V-V_{h}\right)\right]\right.$ $k)]^{-1}$, where $V_{h}$ is the potential of the half-(in)activation and $k$ is the slope factor indicating the steepness of the calculated curve. The equation applies to inactivation and activation curves, $k$ assuming a positive and negative value, and $V$ representing the prepotential and the command potential, respectively. 
ther depolarization, tail currents were contaminated by $I_{\mathrm{L}}$. The duration of the depolarizing commands was set to values near peak current activation, and the tail currents evoked by repolarization to potentials outside the range of $I_{\mathrm{T}}$ activation can be assumed to reflect the T-channels activated during the depolarizing command. Since the repolarizing potential is fixed, tail currents can be normalized and plotted against the command potential to produce an activation curve.

The normalized amplitudes of the tail currents were averaged, plotted against the command step, and a Boltzmann function was approximated to the data points (squares in histogram of Fig. 2). The activation curves of $I_{\mathrm{T}}$ were nearly identical in RT neurons from GAERS $(n=13)$ and NEC $(n=10)$. Activation started at around $-80 \mathrm{mV}$ and was almost complete at $-40 \mathrm{mV}$; the values of half-activation $(-64.0 \pm 1.2$ and $-64.4 \pm 1.8 \mathrm{mV})$ and slope $\left(-4.9 \pm 0.3\right.$ and $\left.-4.7 \pm 0.4 \mathrm{mV}^{-1}\right)$ were not significantly different in GAERS and NEC neurons.

As shown in Figure 3, the amplitude of $I_{\mathrm{T}}$ and $I_{\mathrm{L}}$ increased substantially after birth in RT neurons, and differences in $I_{\mathrm{T}}$ amplitude between GAERS and NEC attained significance after postnatal day 11 . At the same postnatal age, the $I_{\mathrm{T}}$ current in thalamocortical relay neurons isolated from VB was not significantly altered in GAERS in comparison to NEC (see also Guyon et al., 1993).

\section{Discussion}

The choice of the experimental model

The study of the mechanisms underlying epileptic discharges in primary generalized epilepsies requires the utilization of appropriate experimental models, which have to fulfill the criteria described by the terms idiopathic and generalized (Commission on Classification and Terminology of the International League Against Epilepsy, 1989). The strain of Wistar rats with genetically determined seizures designated as GAERS present spontaneous absences correlated with high-amplitude SWDs occurring abruptly on a normal intercritical EEG activity. Neurophysiological, behavioral, genetic, and pharmacological studics carricd out in the past 10 ycars demonstrated that SWDs in GAERS fulfill the requirements for an experimental model of absence epilepsy (Marescaux et al., 1992). The SWD genetic trait in GAERS is inherited, and the onset of seizures is age dependent, starting after 1 month of postnatal life (Vergnes et al., 1986; Marescaux et al., 1992). As for spindles and human generalized SWDs (Kellaway, 1985), seizure occurrence in GAERS increases during phases of transition between arousal and sleep, although the frequency of SWDs in GAERS at 7-11 $\mathrm{Hz}$ (Marescaux et al., 1992) is higher than that $(2-4 \mathrm{~Hz})$ seen in the EEG of petit mal patients (Kellaway, 1985) and in animal experiments using the penicillin model of generalized epilepsy (Gloor and Fariello, 1988) or the cortically or thalamically induced seizure activity in acute and chronic preparations (cf. Avoli et al., 1990). This heterogeneity of SWDs may indicate that multiple mechanisms may be involved in the genesis of different forms of SWDs (cf. Steriade et al., 1993; von Krosigk et al., 1993). In any case, in vivo recordings from the thalamus and cortex in GAERS demonstrated that SWDs were abolished ipsilaterally by a large lesion of the lateral thalamus after a complete callosotomy (Vergnes et al., 1987; Vergnes and Marescaux, 1992). Moreover, Avanzini et al. (1993) demonstrated that SWDs in GAERS are disrupted ipsilaterally to selective lesions of RT induced by stereotaxic injections of the excitotoxine ibotenic acid in previously callosotomized animals. Similarly, in- organic $\mathrm{Ca}^{2+}$ antagonists suppressed SWDs when locally infused in RT and only reduced their expression when injected in the lateral thalamic relay nuclei (Vergnes et al., 1987; Avanzini et al., 1993). These data strongly suggested that $\mathrm{Ca}^{2+}$-dependent processes in RT are determinant in the regulation of SWDs in GAERS, and they achieve particular relevance in light of the demonstration in isolated thalamic neurons that the transient calcium current $I_{\mathrm{T}}$, critical for the generation of oscillatory behavior, is reduced by antiepileptic drugs effective on absence seizures and on GAERS SWDs, like ethosuccimide (Marescaux et al., 1984; Coulter et al., 1989b, 1990; Huguenard and Prince, 1992, 1994a).

\section{Selective $\mathrm{I}_{T}$ increase in $R T$}

The present study demonstrates that in GAERS the transient $\mathrm{Ca}^{2+}$ conductance $I_{\mathrm{T}}$ is selectively augmented in neurons of the RT after the second postnatal week. This alteration seems to be selective in terms of the type of $\mathrm{Ca}^{2+}$ conductance and the type of thalamic neuron that are affected, since the L-type current component was not affected in the same sample of RT neurons, and $\mathrm{Ca}^{2+}$ currents were not significantly different in thalamocortical relay neurons isolated from the VB complex of the same animals. The latter result confirms the observation by Guyon et al. (1993) of unaltered $\mathrm{Ca}^{2+}$ currents in VB slices obtained from adult GAERS. The observed enhancement of $I_{\mathrm{T}}$ amplitude is not due to differences in membrane surface area or postnatal age of the two populations of RT neurons that were studied, and it is not likely to result from an alteration in the gating properties of the underlying conductance, since activation and inactivation curves and the kinetics of the current were similar in neurons dissociated from NEC and GAERS. Following from this, the augmented $I_{\mathrm{T}}$ current in RT neurons from GAERS seems to reflect an increase in the number of available T-type $\mathrm{Ca}^{2+}$ channels or an increase in single channel conductance, thereby resembling the transient enhancement of $I_{\mathrm{T}}$ demonstrated in relay neurons after cortical lesions (Chung et al., 1993).

A transient $\mathrm{Ca}^{2+}$ current with a nearly voltage-independent, slow rate of inactivation and a rather positive range of activation $\left(V_{h}=-49 \mathrm{mV}\right)$, designed as $I_{\mathrm{r}}$, has been demonstrated by $\mathrm{Hu}-$ guenard and Prince (1992) in neurons isolated predominantly from the most anterior section of the thalamus. The neurons from the dorsal, VB-related portion of the RT studied in the two laboratories participating in the present study (see Materials and Methods) possessed a more rapidly inactivating $I_{\mathrm{T}}$ with negative range of activation $\left(V_{h}=-64 \mathrm{mV}\right)$. This heterogeneity suggests that the $I_{\mathrm{T}}$ may be selectively segregated in neurons of the most anterior portion of RT, where neurons also present morphological features different from those of the more caudal RT (Scheibel and Scheibel, 1972; Spreafico et al., 1991; Luibke, 1993), or that two classes of neurons possessing distinctive electrophysiological properties may exist in the RT nucleus (Contreras et al., 1992).

\section{Increased synchronization and SWDs}

Several lines of evidence summarized in the introduction indicate that common circuitry and intrinsic mechanisms in the thalamus, of which reciprocal intrathalamic connections and burst firing dependent on the T-type $\mathrm{Ca}^{2+}$ conductance represent two important variables, underlie spindle rhythm and SWDs of absence epilepsy. We suggest that the selective, presumably genetically determined, increase in the conductance underlying $I_{\mathrm{T}}$ in RT neurons enhance the propensity for burst firing, thereby 
A

$$
I_{\mathrm{T}}
$$

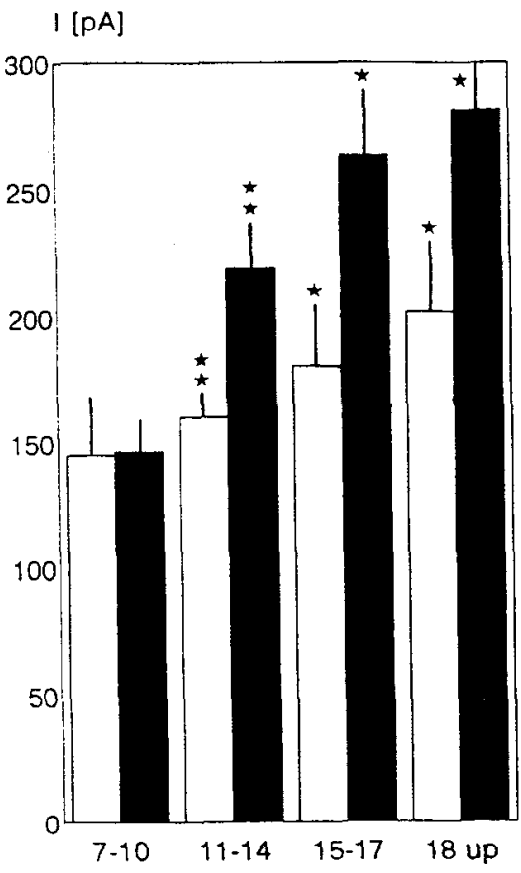

B

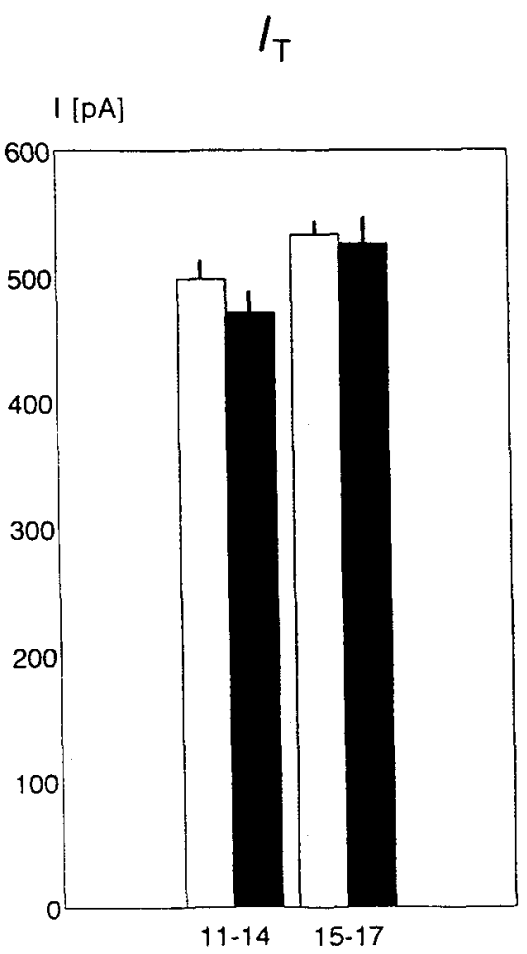

postnatal day

\section{RT}

1 [PA]

$\square$ Control

GAERS

I

\section{(1)}

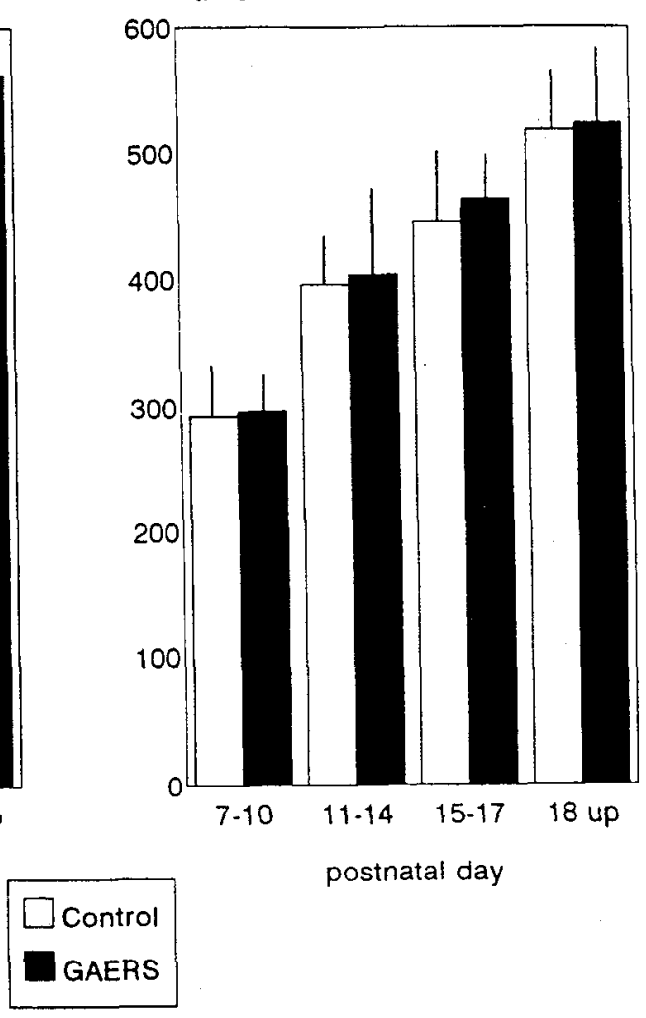

VB<smiles>C1CCC1</smiles>

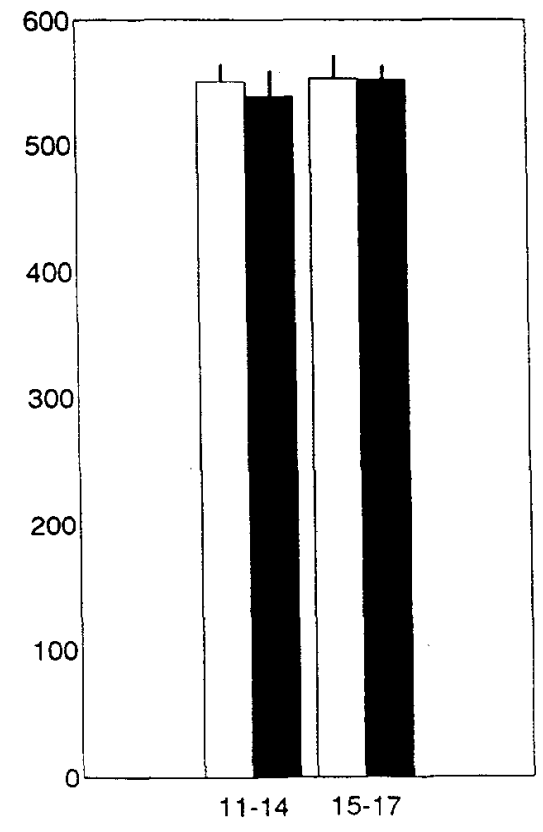

postnatal day
Figure 3. Age-dependent and selective increase of $I_{T}$ in RT neurons from GAERS. Mean maximal amplitudes of $I_{\mathrm{T}}$ and $I_{\mathrm{L}}$ in RT neurons $(A)$ and relay neurons from VB $(B)$ acutely dissociated from GAERS (closed bars) and NEC (control; open bars) at different postnatal ages. Note the selective increase in $I_{\mathrm{T}}$ in GAERS starting at postnatal days 11-14. Bars represent averaged data ( \pm SEM); significant differences between GAERS and NEC are indicated by asterisks (**, $p<$ $0.01 ; * *, p<0.05$; two-tailed $t$ test). To account for possible differences in cell size at different postnatal days, current amplitudes were normalized to a membrane surface area corresponding to an input capacitance of $20 \mathrm{pF}$. 
entraining recurrent burst activity and contributing to the pathological increase in synchronization underlying SWDs in GAERS. In line with this hypothesis is the recent observation in thalamic slice preparations that the decrease $(30-40 \%)$ in $I_{\mathrm{T}}$ conductance by succinimides resulted in a dramatic reduction in intrathalamic oscillations through a slight decrease in burst probability of thalamic neurons (Huguenard and Prince, 1994b). The $\mathrm{Ca}^{2+}$ currents in thalamocortical relay neurons in VB and possibly in other thalamic nuclei are not affected in GAERS, but relay cells can be assumed to be secondarily recruited by the rhythmic discharges generated in RT. In addition, an increase in $\mathrm{GABA}_{\mathrm{B}}$ receptor-mediated responsiveness (Snead, 1992; Hosford et al., 1992) and resulting increase in deinactivation of $I_{\mathrm{T}}$ in relay cells may act to reinforce recurrent rhythmic discharges into pathological forms of synchronization on the level of the relay nuclei (Von Krosigk et al., 1993).

The fact that seizures and SWDs in human absence epilepsy and in genetic animal models are age dependent and are usually absent at birth suggests that the pathological expressivity of the original defect (or defects) depends on the complete maturation of neuronal elements and synaptic circuitry in the thalamocortical system. In GAERS, both the increase in $I_{\mathrm{T}}$ amplitude and the appearance of SWDs are absent at early postnatal stages. Their later developmental course diverges considerably, since $I_{\mathrm{T}}$ augmented with respect to controls $11 \mathrm{~d}$ after birth, whereas SWDs are undetectable before the end of the first month of postnatal life. It is conceivable that, as for the physiological thalamocortical synchronizing patterns (Jouvet-Mournier et al., 1970), SWD expression in GAERS requires the complete maturation of the thalamocorticothalamic synaptic network to become fully expressed. It is known that maturation of thalamic and cortical connections in rats is completed within 2 weeks of postnatal age (Jones, 1985). By comparison, other processes such as synaptogenesis and spine formation, which control postsynaptic potential generation in the thalamus and cortex and which are probably needed to express functionally mature rhythmic and synchronous thalamocortical oscillations, are modified during later phases of development and do not reach near-adult stages before the fourth postnatal week (Cragg, 1975; Daniels et al., 1975; Wise et al., 1978; Jones, 1985; for a review see Shatz, 1990).

Changes in the quantitative expression of a single current or membrane receptor during the thalanocortical developmental time table paced by a programmed sequence of gene expression (Desarmenian et al., 1992; Spitzer et al., 1994) may significantly modify the synaptic arrangement and the weight of synapses in a developing network. The possibility that such a process is active in the ontogenesis of SWD generation is strengthened by the notion that synaptic activity and rhythmic oscillations play an important role in organizing synaptic connectivity (Changeaux and Danchin, 1976; Provine and Rogers, 1977; Llinás, 1984; Llinás, 1988; Shatz, 1990; Kalb and Hockfield, 1992; Sil lar, 1994). It is known from these studies that during development, neurons produce electrical autorhythmicity, which can entrain homogeneous populations of neurons to oscillate. Network oscillations lead to a dynamic linkage between different brain areas and may reinforce synaptic interactions. Oscillatory rhythmic activity at various frequencies, whose relevance in normal physiological conditions can be easily appreciated by looking at the EEG of an infant, may be an important factor in determining the strength and the ontogenic organization of synaptic connectivity that are necessary to regulate a complex func- tion. The abnormal thalamic oscillatory activity generated in juvenile GAERS by the augmented $I_{\mathrm{T}}$ in RT neurons could, in principle, consolidate excitatory synapses and influence the plastic properties of developing thalamic and cortical neurons toward a persistent state of hyperexcitation, which is expressed by SWDs.

The selective increase in $I_{\mathrm{T}}$ conductance in RT neurons is the first demonstration of a primary neuronal dysfunction suspected to relate to seizure generation in an established animal model of genetic epilepsy and represents a potentially important step in the attempt to identify markers for genetic linkage studies in human epilepsies.

\section{References}

Avanzini G, de Curtis M, Sprcafico R (1989) Intrinsic properties of nucleus reticularis neurons of the rat studied in vitro. $\mathbf{J}$ Physiol (Lond) 416:111-122.

Avanzini G, Vergnes M, Spreafico R, Marescaux C (1993) Calciumdependent regulation of genetically determined spike and waves by the RTN of rats. Epilepsia 34:1-7.

Avoli M, Gloor P (1982) Role of thalamus in generalized penicillin epilepsy: observations on decorticated cats. Exp Neurol 77:386-402.

Avoli M, Gloor P, Kostopoulos G, Naquet R (1990) Generalized epilepsy: neurobiological approaches. Boston: Birkhauser.

Bal T, McCormick DA (1993) Mechanisms of oscillatory activity in guinea pig nucleus RT in vitro: a mammalian pacemaker. J Physiol (Lond) 468:669-691.

Berkovic JC, Andermann F, Andermann E, Gloor P (1987) Concepts of absence cpilepsics: discrete syndromes or biological continuum? Neurology 37:993-1000.

Budde T, Mager R, Pape H-C (1992) Different types of potassium outward current in relay neurons acutely isolated from the rat lateral geniculate nucleus. Eur J Neurosci 4:708-722.

Changeaux JP, Danchin A (1976) Selective stabilization of developing synapses as a mechanism for the specification of neuronal networks. Nature 264:705-712.

Chung J-M, Huguenard JR, Prince DA (1993) Transient enhancement of low-threshold calcium current in thalamic relay neurons after corticecomy. J Neurophysiol 70:20-27.

Commission on Classification and Terminology of the International League Against Epilepsy (1989) Proposal for revised classification of epilepsies and epileptic syndromes. Epilepsia 30:389-399.

Contrcras D, Currló Dossi R, Steriade M (1992) Bursting and tonic discharges in two classes of reticular thalamic neurons. J Neurophysiol 68:973-977.

Coulter DA, Huguenard JR, Prince DA (1989d) Calciurn currents in rat thalamocortical relay neurons: kinetic properties of the transient, low-threshold current. J Physiol (Lond) 414:587-604.

Coulter DA, Huguenard JR, Prince DA (1989b) Characterization of ethosuximide reduction of low-threshold calcium current in thalamic neurons. Ann Neurol 25:582-593.

Coulter DA, Huguenard JR, Prince DA (1990) Differential effect of petit mal anticonvulsants and convulsants on thalamic neurons: calcium current reduction. Br J Pharmacol 100:800-806.

Cragg BG (1975) Development of synapses in the visual system of the cat. J Comp Neurol 160:147-166.

Crunelli V, Lightowler S, Pollard CE (1989) A T type calcium current underlies low threshold calcium potentials in cells of the cat and rat lateral geniculate nucleus. J Physiol (Lond) 413:543-561.

Daniels JD, Pettigrew JD, Norman JL (1978) Developnient of single unit responses in kitten's LGN. J Neurophysiol 41:1373-1393.

Gloor P, Fariello RG (1988) Generalized epilepsy: some of its cellular mechanisms differ from those of tocal epilepsy. 'Irends Neurosci 11 : 63-68.

Guyon M, Vergnes M, Leresche N (1993) Thalamic low threshold calcium current in a genetic model of absence epilepsy. Neuroreport 4:1231-1235.

Hamill OP, Marty A, Neher F, Sakmann B, Sigworth FJ (1981) Improved patch clamp techniques for high resolution current recordings from cells and cell-free membrane patches. Pfluegers Arch 391:85100 .

Hernández-Crus A, Pape H-C (1989) Identification of two calcium cur- 
rents in acutely dissociated neurons from the rat geniculate nucleus. J Neurophysiol 61:1270-1283.

Hosford DA, Clark S, Cao Z, Wilson WA, Lin F-H, Morrisett RA, Huin A (1992) The role of $\mathrm{GABA}_{\mathrm{B}}$ receptor activation in absence seizures of lethargic $(l h / l h)$ mice. Science 257:398-401.

Huguenard JR, Prince DA (1992) A novel T-type current underlies prolonged calcium-dependent burst firing in GABAergic neurons of rat RT. J Neurosci 12:3804-3821.

Huguenard, JR, Prince DA (1994a) Clonazepam suppresses GABA $_{B}$ mediated inhibition in thalamic rclay ncurons through effects in nucleus reticularis. J Neurophysiol 71:2576-2581.

Huguenard JR, Prince DA (1994b) Intrathalamic rhythmicity studied in vitro: nominal $\mathrm{T}$ current modulation causes robust anti-oscillatory effects. J Neurosci 14:5485-5502.

Inoue M, Duysens J, Vossen JMH, Coenen AML (1993) Thalamic multiple unit activity underlying SWD in anesthetized rats. Brain Res 612:35-40.

Jahnsen H, Llinás RR (1984) Ionic basis for the electroresponsiveness and oscillatory properties of guinea pig thalamic neurons in vitro. $\mathrm{J}$ Physiol (Lond) 349:227-247.

Jasper HH, Droogleever-Fortuyn J (1946) Experimental studies of the functional anatomy of the petit mal epilepsy. Res Publ Assoc Res Nerv Ment Disord 26:272-290.

Jasper HH, Kershman J (1941) Electroencephalographic classification of the epilepsies. Arc Neurol Psychiatry 45:903-943.

Jones EG (1985) The thalamus. New York: Plenum.

Jouvet-Mournier D, Astic L, Lacote M (1970) Ontogenesis of the states of sleep in rat, cat and guinea pig during the first postnatal month. Dev Psychobiol 2:216-239.

Kalb RG, Hockfield S (1986) Activity dependent development of spinal chord motor neurons. Brain Res Rev 17:283-289.

Kay AR, Wong RKS (1986) Isolation of neurons suitable for patchclamping from adult mammalian central nervous system. J Neurosci Methods 16:227-238.

Kellaway P (1985) Sleep and epilepsy. Epilepsia 26:S15-S30.

Liu Z, Vergnes M, Depaulis A, Marescaux C (1992) Involvement of intrathalamic GABAb neurotransmission in the control of absence seizures in the rat. Neuroscience 51:87-93.

Llinás RR (1984) Possible role of tremor in the organization of the nervous system. In: Movement disorders: tremor (Findley LJ, Capildeo R, eds), pp 473-478. London: Macmillan.

Llinás RR (1988) The intrinsic electrophysiological properties of mammalian neurons: insight into the central nervous system functions. Science 242:1654-1664.

Luibke J (1993) Morphology of neurons in the thalamic reticular nuclcus (TRN) of mammals revealed by intracellular injections into fixed brain slices. J Comp Neurol 329:458-471.

Marescaux C, Vergnes M, Micheletti G (1984) Antiepileptic drug evaluation in a new animal model: spontaneous petit mal apilepsy in the rat. Fed Proc 43:280-281.

Marescaux C, Vergnes M, Depaulis A (1992) Genetic absence epilepsy in rats from Strasbourg-a review. J Neural Transm 35:37-69.

McCormick DA (1992) Neurotransmitter actions in the thalamus and cerebral cortex and their role in neuromodulation of thalamocortical activity. Prog Neurobiol 39:337-388.

Metrakos K, Metrakos J (1961) Genetic of convulsive disorders. II.
Genetic and EEG studies in centrencephalic epilepsy. Neurology 11: 474-483.

Pape H-C, Budde T, Mager R, Kisvárday ZF (1994) Prevention of $\mathrm{Ca}^{2+}$-mediated action potentials in GABAergic local circuit neurons of the rat thalamus by a transient $\mathrm{K}^{+}$current. J Physiol (Lond) 478: $403-422$.

Pirchio M, Lightowler S, Crunelli V (1990) Postnatal development of the T-calcium current in cat thalamocortical cells. Neuroscience 38: 39-45.

Prince DA, Farrel D (1969) Centrencephalic SWD following parenteral penicillin injection in the cat. Neurology 19:309-310.

Provine RR, Rogers L (1977) Development of spinal chord bioelectrical activity in spinal chick embryos and its behavioural implications. J Neurobiol 8:217-228.

Roger J, Dravet C, Bureau M (1985) Epileptic syndromes in infancy, childhood and adolescence. London: Libbey.

Scheibel ME, Scheibel AB (1972) Specialized organizational patterns within the RT nucleus of the cat. Exp Neurol 34:316-322.

Shatz, CJ (1990) Impulse activity and the patterning of connections during CNS development. Neuron 5:745-756.

Sillar KT (1994) Synaptic specificity: development of locomotor rhythmicity. Curr Opin Neurosci 4:101-107.

Snead OC (1992) Evidence for $\mathrm{GABA}_{\mathrm{B}}$-mediated mechanisms in experimental generalized absence seizures. Eur J Pharmacol 213:343349.

Spiegel EA, Wycis HT (1950) Thalamic recordings in man with special reference to seizure discharges. EEG Clin Neurophysiol 2:23-27.

Spreafico R, Battaglia G, Frassoni C (1991) The RT nucleus of the rat cytoarchitecture, Golgi, immunocytochemical and HRP study. J Coinp Neurol 304:478-490.

Steriade M, Deshenes M (1984) The thalamus as a neuronal oscillator. Brain Res Rev 8:1-31.

Steriade M, Llinas RR (1988) The functional states of the thalamus and the associated neuronal interplay. Physiol Rev 68:649-742.

Steriade M, Domich L, Oakson G (1986) Reticularis thalami neurons revisited: activity changes during shifts in states of vigilance. J Neurosci 6:68-81.

Steriade M, Domich L, Oakson G (1987) The deafferented reticular thalamic nucleus generates spindle rhythmicity. J Neurophysiol 57: 260-273.

Steriade M, McCormick DA, Sejnowski TJ (1993) Thalamocortical oscillations in the sleeping and aroused brain. Science 262:679-685.

Vergnes M, Marescaux C (1992) Cortical and thalamic lesions in rats with genetic absence epilepsy. J Neural Transm 35:71-83.

Vergnes M, Marescaux C, Depaulis A, Micheletti G, Warter JM (1986) Ontogeny of spontaneous petit mal-like seizures in Wistar rats. Dev Brain Res 30:85-87.

Vergnes M, Marescaux C, Depaulis A, Micheletti G, Warter JM (1987) Spontaneous SWD in thalamus and cortex in a rat model of genetic petit mal epilepsy. Exp Neurol 96:127-136.

von Krosigk M, Bal M, McCormick DA (1993) Cellular mechanisms of a synchronized oscillation in the thalamus. Science 261:361-364.

Williams D (1953) Study of thalamic and cortical rhythms in petit mal. Brain 76:50-69.

Wise SP, Fleshman J Jr, Jones EG (1978) Developmental study of thalamocortical and commissural connections in the rat somatic sensory cortex. J Comp Neurol 178:187-208. 